\title{
Volatility of Internally Generated Revenue and Effects of Its Major Components: A Case of Akwa Ibom State, Nigeria
}

\author{
Usoro Anthony Effiong, John Eme Eseme \\ Department of Statistics, Faculty of Physical Sciences, Akwa Ibom State University, Mkpat Enin, Nigera \\ Email address: \\ anthonyusoro@aksu.edu.ng (U. A. Effiong)

\section{To cite this article:} \\ Usoro Anthony Effiong, John Eme Eseme. Volatility of Internally Generated Revenue and Effects of Its Major Components: A Case of Akwa \\ Ibom State, Nigeria. American Journal of Theoretical and Applied Statistics. Vol. 8, No. 6, 2019, pp. 276-286. \\ doi: 10.11648/j.ajtas.20190806.19
}

Received: October 13, 2019; Accepted: November 12, 2019; Published: December 4, 2019

\begin{abstract}
In this work, volatility of Internally Generated Revenue of Akwa Ibom State with the contributory effects of its components was the major interest. Autoregressive Conditional Heteroscedasticity ARCH (1) model adopted revealed volatility in the IGR. This motivated investigation of the components as contributory factors to the volatility. The OLS regression of IGR volatility on the K-components revealed the contribution of each component to the IGR volatility. The F test result showed overall fitness of the regression model. Individual $\mathrm{T}$ test placed tax revenue volatility higher than any other component. The volatility in the tax revenue is explained by the inconsistency in the growing trend of the tax revenue. This is attributed to laxities in the revenue generation mechanism, therefore posing challenges to the revenue system. The revenue generation system in the state requires sound leadership in the Board of Internal Revenue, good revenue driven policy, transparent tax revenue consulting and innovative approaches by the labour force for improved revenue system. Government willingness to address the prevailing issues would enhance stability in the revenue generation, therefore, helping to reduce volatility and cope with the challenges of financial planning in Akwa Ibom State.
\end{abstract}

Keywords: Volatility, Autoregressive Conditional Heteroscedasticity, Internally Generated Revenue, Tax Revenue

\section{Introduction}

There is no gainsaying the fact that internally generated revenue, be it at the federal, state or local government level is a major concern as government desires to increase its revenue capacity so as to effectively surmount some financial challenges in a bid to offer needed services for development of the society. Apart from external aid, every level of government principally depends on two sources of revenue; the federation account and internally generated revenue. The role of internally generated revenue to the government cannot be overemphasized. This explains the reason for government commitment to increase in revenue generation.

Revenue generation is observed to exhibit some nonlinearity characteristics due to certain factors. In Akwa Ibom State, in particular, the relevant government authority saddled with the responsibility of revenue generation is Board of Internal Revenue. To complement the effort of the Board in boosting the revenue generation, different revenue consultants have been engaged by the state Government since 1995 to generate revenue for the state. The introduction of revenue consultants to the state was a hope for improved revenue generation and significant reduction in variability or discrepancy between the yearly budgeted and the actual IGR of the state. So far, the desired goal is yet to be achieved. High variability accounts for non-linearity of the revenue series. This explains the reason why some revenue researchers face challenges of inadequacy classical linear time series models in fitting revenue series due to nonlinearity of the series. Facts have been established that most of the revenue series possess some characteristics of volatility clustering in certain time periods. This volatility describes wide swings of revenue for an extended time period followed by periods of short swings. Volatility periods are periods of high level of uncertainty in the revenue generation, antonymous with periods of relative calm which describe low variability between the expected and actual revenue. Like in financial time series, such as stock prices, exchange rates, inflation rates, volatility is of crucial 
important in revenue series because of certain economic factors and government policies that account for large positive and large negative observations in the internally generated revenue, [13]. One of the reasons for capturing volatility in revenue series is that it is important for prospective planning, especially when government or relevant agency desires to investigate and make decisions about the structure of revenue sources on which government depends upon for certain services it renders [3, 8]. Yan [19] and Rodriguez [14] proposed using revenue volatility as an independent variable in making decisions about revenue structure, the use of rainy day funds, or state borrowing trends. This is in agreement with the fact that interest in revenue should not only be limited to the total or average revenue any level of government makes, but also the variability or volatility, the individual components that constitute volatility to the total IGR. The analysis of the volatility of the revenue components becomes necessary in this paper because volatility in IGR is not independent of volatility of the revenue sources.

Akwa Ibom State Internally Generated Revenue is aggregated by many components. The major components of interest in this paper include, Taxes, Fines \& Fees, Licenses and Earnings \& Sales. The underlying assumption in this paper is that there exists volatility clustering in the revenue series due to high variability. The problem is that volatility assumed to exist in the IGR is caused by its components as the sources and contributors to the internally generated revenue. By this proposition, this paper is motivated by the need to identify the components of IGR that have exerted influence and constituted volatility clustering to the internally generated revenue in Akwa Ibom State. It is believed that the idea to identify volatility clustering in the revenue sources would help the government of Akwa Ibom State to control excessive variability in individual components reputed to account for high volatility of the IGR and also improvise measures of managing long-term revenue fluctuations, avoid making short-term gains and raises the hope of adequate and justifiable resources in reserve. If the volatility in the revenue series and its sources are well studied and checked, proper management of the long periods of high variance could be reduced, as these would account for less swings in the revenue series over time, and therefore characterising steady movement in the revenue series for easy forecast and planning.

\section{Literature Review}

A lot of researches have been carried out on volatility of revenue and financial data. Researchers have contributed in the analyses and modelling of volatility of revenue and financial data. It is always very challenging when a classical linear time series model, such as Autoregressive Integrated Moving Average (ARIMA) model is used for the analysis of volatility. ARIM model is a model that establishes linear relation between a time series process and its distributed lags. The limitation in the use of ARIMA model is that it is difficult for ARIMA model to capture high level of fluctuations in a time process. Sequel to this development, Granger and Anderson introduced bilinear time series with the aim to take care of the non-linear component of the time dependent variable, [9]. Bilinear time series models are found useful in fitting revenue data of a local government area in Akwa Ibom State, [17]. Some special classes of bilinear time series models have been identified under certain conditions, [16, 18]. These included Bilinear Autoregressive (BAR) models and Bilinear Moving Average (BMA) models. The above literatures were limited to the use of bilinear time series models in modelling revenue series. In a comparative study between bilinear model, Autoregressive Conditional Heteroscedasticity $(\mathrm{ARCH})$ and Generalised Autoregressive Conditional Heteroscedasticity (GARCH) model, the findings showed that ARCH and GARCH models outperformed bilinear model [2]. The use of ARCH and GARCH models has become more prominent with increasing interest in the study of volatility of revenue and financial variables. The dynamic of inflation volatility in Nigeria using GARCH, TGARCH and EGARCH models has been investigated. Volatilities of Headline Consumer Price Index, Food Consumer Price Index and Core Consumer Price Index were investigated. The results revealed TGARCH $(1,1)$ model with minimum AIC as the best for Headline CPI and Core CPI, while GARCH $(1,1)$ was the best for Food CPI [1].

Different ARCH, GARCH and Bilinear models have been adopted in the investigations of volatility of exchange rate of Naira/USD, Naira/BP and Naira/Euro returns, Nigerian Stock Market Returns Volatility, Naira-US dollar and Naira-Special Drawing Rights (SDR). The results showed that N-SDR was more volatile than N-USD, [5, 11, 15, 20].

In stock market, Kenyan stock market volatility is analysed using GARCH model, [12]. The result showed evidence of volatility clustering over time. Application of GARCH models also included volatility in Jordan's Stock Market. The study applied ARCH, GARCH and EGARCH to investigate the behaviour of volatility in the stock return series. Better results were obtained with $\mathrm{ARCH}$ and GARCH models, [6]. The comparative predictive accuracy of nonlinear asymmetry volatility models in the analysis of twelve bank shares is carried out, [21]. The results reputed APARCH model to be the best among the suggested models. These were revealing, because looking at the plot of the various bank share prices, evidence of linearity was not observed in each of the graphs. Revenue volatility, public budgeting and finance are well fitted with exponential trend model, [4]. The volatility was estimated from the residual of the exponential model. Tourism receipts volatility of countries have been modelled, [7]. Volatility model based of portfolio approach for the analysis of tax revenue has been developed, [10]. The use of the portfolio approach was to allow for the computation of the total share of tax that would minimise the variability in total tax revenue. The model was useful as well as other parametric volatility model. 
It suffices to say that some revenue and financial variables are independently studied and analysed. Some are dependent upon their sources whose contributions account for the variable characteristics. The gab between this paper and reviewed literature is that this paper is not limited to the study of volatility of the internally generated revenue as a variable. Volatilities of the independent sources of the IGR are of interest in this research. The importance of examining the volatility of the internally generated revenue and its components is explained by the concept of elasticity in economic theory. The sensitivity in the volatility of the IGR is with respect to volatilities in its components. That means volatilities of the revenue components account for the volatility of the IGR. Therefore, it is researchable to examine the volatilities of the revenue sources that constitute the volatility of the internally generated revenue. The interest in studying volatilities of the revenue components is pertinent in this work because contributions of individual component volatilities cannot be the same. Volatilities of some components may be significant and some may not be. In the course of the analysis, some components found to significantly contribute to high volatility clustering of IGR would be identified, checked and control for efficient and smooth revenue generation and effective government development plan.

\section{Methodology}

\subsection{Preliminary Investigation}

Let $\mathrm{X}_{1 \mathrm{t}}$ represent the Internal Generated Revenue of Akwa Ibom State, $\mathrm{X}_{2 \mathrm{t}}, \mathrm{X}_{3 \mathrm{t}}, \mathrm{X}_{4 \mathrm{t}}$ and $\mathrm{X}_{5 \mathrm{t}}$ represent Tax Revenue (TR), Fines and Fees (FF), Licences (L) and Earnings and Sales (ES) respectively as major components of the IGR.

The Internally generated Revenue return series is defined by

$$
R_{1 t}=\log \left(\frac{X_{1 t}}{X_{1 t-1}}\right)
$$

where $R_{1 t}$ is the log return series of the IGR, $X_{1 t}$ and $X_{1 t-1}$ are the raw data of IGR at times $t$ and $t-1$.

The mean of $\mathrm{R}_{1 \mathrm{t}}$, Mean $\left(\mathrm{R}_{1 \mathrm{t}}\right)=\mathrm{E}\left(\mathrm{R}_{1 \mathrm{t}}\right)=\mu_{t}$

Variance of $\mathrm{R}_{1 \mathrm{t}}$, $\operatorname{Var}\left(\mathrm{R}_{1 \mathrm{t}}\right)=E\left(R_{1 t}-\mu_{t}\right)^{2}=Y_{1 t}^{2}$

Let $R_{2 t}, R_{3 t}, R_{4 t}$ and $R_{5 t}$ be return series for $X_{2 t}, X_{3 t}, X_{4 t}$ and $\mathrm{X}_{5 \mathrm{t}}$ respectively.

Let $Y_{2 t}, Y_{3 t}, Y_{4 t}$ and $Y_{5 t}$ be the variances for $X_{2 t}, X_{3 t}, X_{4 t}$ and $\mathrm{X}_{5 \mathrm{t}}$ respectively.

Figures $1-5$ are the plots of log return series against time.

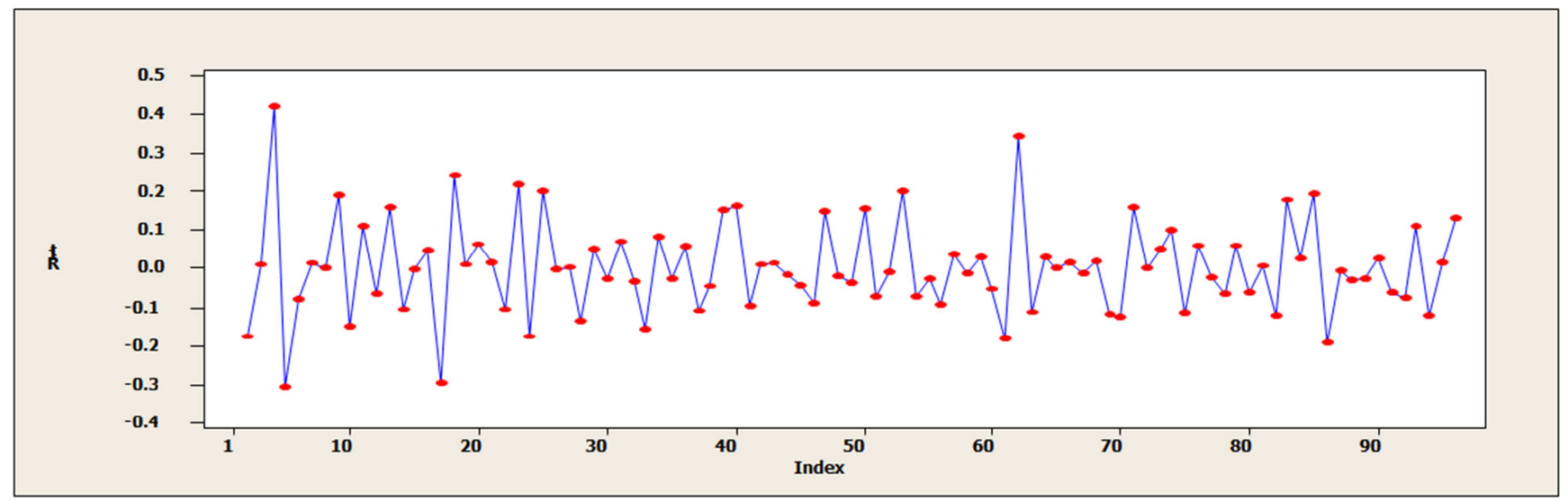

Figure 1. Graph of IGR Return Series $\left(R_{1 t}\right)$.

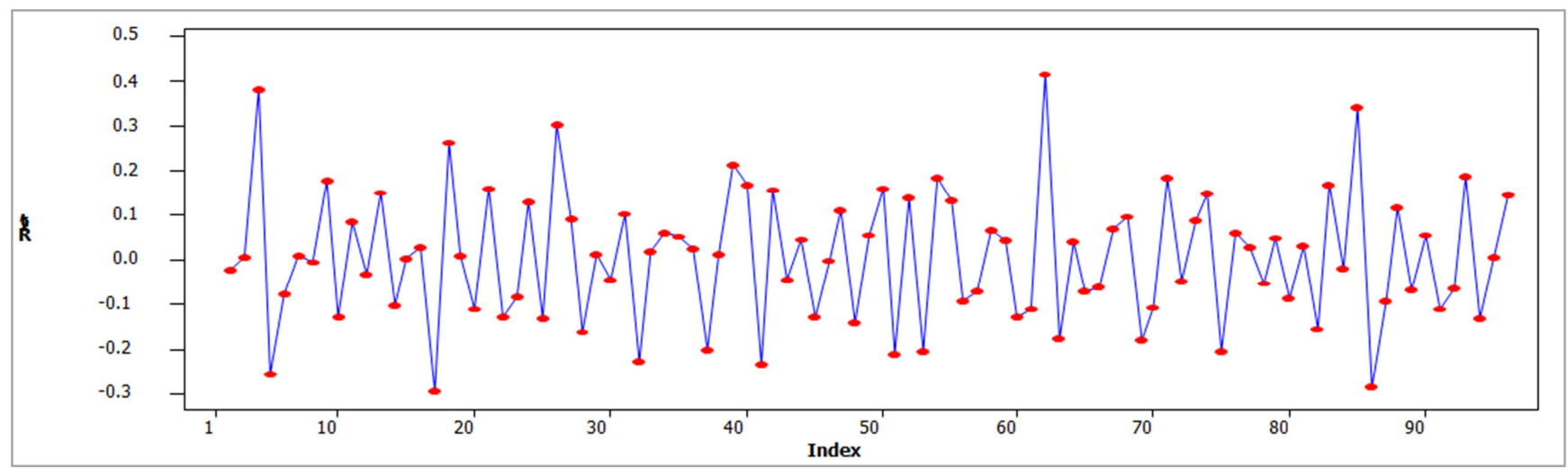

Figure 2. Graph of Tax Return Series $\left(R_{2 t}\right)$. 


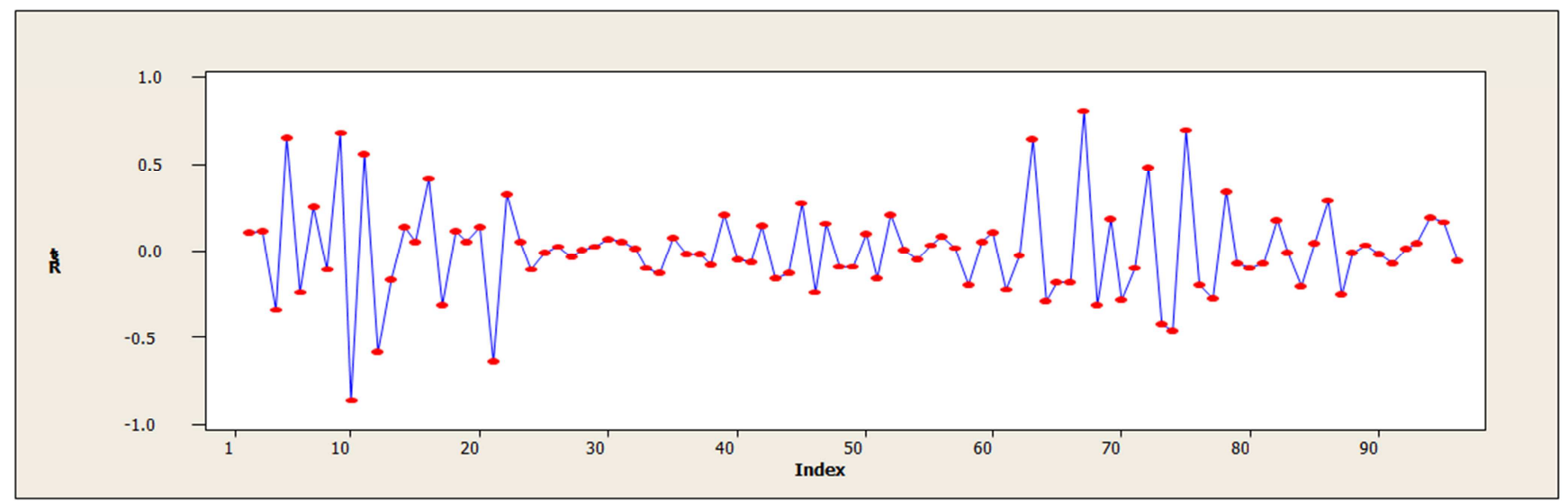

Figure 3. Graph of Fines and Fees Return Series $\left(R_{3 t}\right)$.

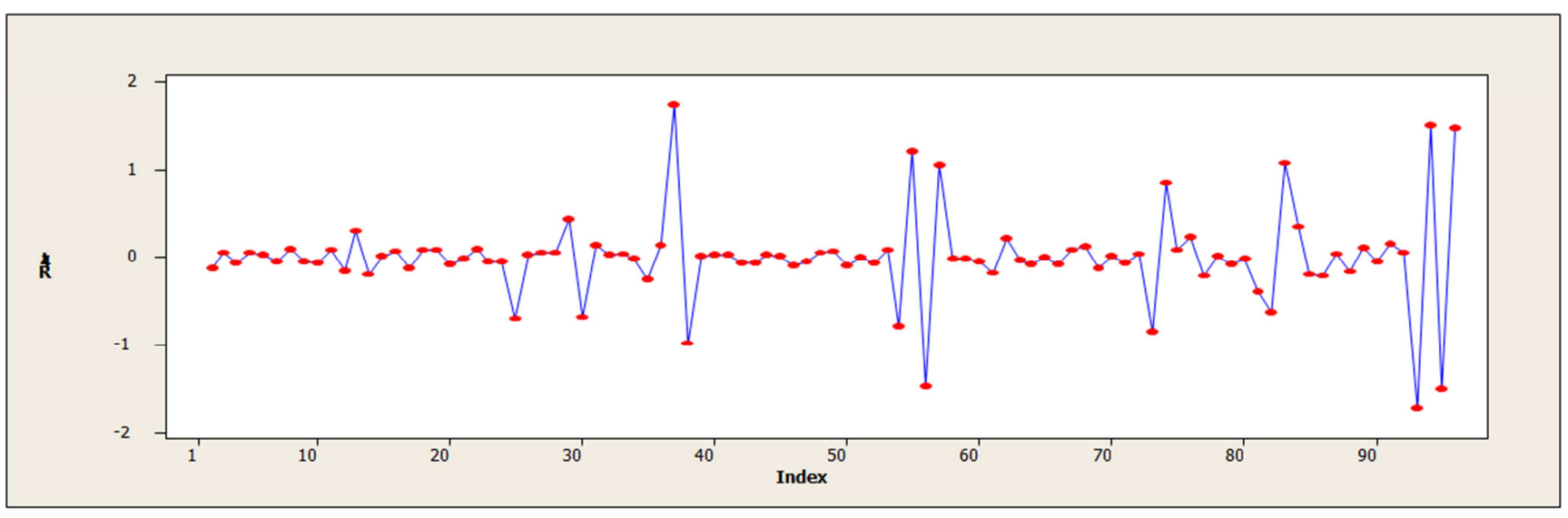

Figure 4. Graph of Fines and Fees Return Series $\left(R_{4 t}\right)$.

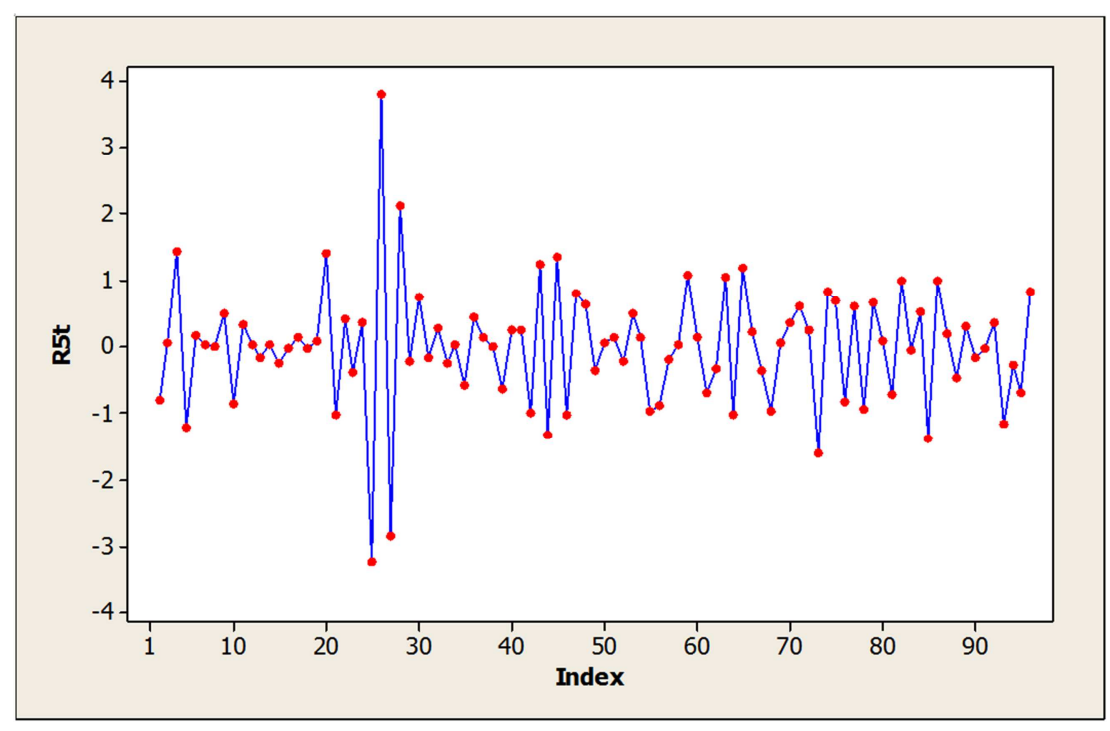

Figure 5. Graph of Fines and Earnings and Sales Series $\left(R_{5 t}\right)$.

From the above plots, it is observed that the relative changes in the IGR and other components show periods of wide, moderate and low swings for some time periods. IGR and Tax return series show wide swings for long time periods. Fines \& Fees and Earnings \& Sales exhibit moderate swings for some time periods, while Licences exemplify very short periods of swings and long periods of low volatility. These explain the phenomenon of volatility in the revenue series.

\subsection{Autoregressive Conditional Heteroscedasticity (ARCH) Model}

The variance $Y_{1 t}^{2}$ is a measure of volatility of the Internally Generated Revenue. Being a squared quantity, its value will be high in periods when there are big changes in the revenue. 
The ARCH (q) model is given by

$$
Y_{1 t}^{2}=\beta_{0}+\beta_{1} Y_{1 t-1}^{2}+\beta_{2} Y_{1 t-2}^{2}+\cdots+\beta_{p} Y_{1 t-p}^{2}+U_{1 t}
$$

The above model reduces to

$$
Y_{1 t}^{2}=\beta_{0}+\sum_{i=1}^{q} \beta_{i} Y_{1 t-i}^{2}+U_{1 t}
$$

Where, $Y_{1 t}^{2}$ is a measure of volatility, $\beta_{0} \geq 0, \beta_{i} \geq i=$ $1,2, \ldots, q, U_{1 t}$ is a white noise process distributed with zero mean and variance $\sigma_{u t}^{2},[10]$.

\subsection{Testing for the Presence of ARCH}

(a) ARCH Effect of $Y_{1 t-i}^{2}$ on $Y_{1 t}^{2}$

From the normal regression of $Y_{1 t}^{2}$ on $Y_{1 t-i}^{2}$, the null hypothesis

$\mathrm{H}_{0}: \beta_{i}=0(i=1,2, \ldots, q)$ against $\mathrm{H}_{1}: \beta_{i} \neq 0$ can be tested for individual coefficients or usual $\mathrm{F}$ test.

Alternatively,

Computation of $n R^{2}, R^{2}$ is the coefficient of determination, $\mathrm{n}$ is the length of the series.

$$
\mathrm{LM}=n R^{2} 2
$$

Where, LM is called Langrage Multiplier. For large sample data,

$$
n R^{2} \sim \chi_{k}^{2}
$$

(b) ARCH Effects of $Y_{2 t}^{2}, Y_{3 t}^{2}, Y_{4 t}^{2}$ and $Y_{5 t}^{2}$ on $Y_{1 t}^{2}$

From the original series, $X_{2 t}, X_{3 t}, X_{4 t}$ and $X_{5 t}$ are components of $X_{1 t}$. If a linear regression of $X_{1 t}$ can be conducted on k-number of variables $\mathrm{X}_{2 \mathrm{t}}, \mathrm{X}_{3 \mathrm{t}}, \mathrm{X}_{4 \mathrm{t}}$ and $\mathrm{X}_{5 \mathrm{t}}$, it implies that the relationship between $\mathrm{X}_{1 \mathrm{t}}$ and its components is established. This further explains the contribution of each $\mathrm{X}_{\mathrm{i}}(\mathrm{i}$ $=2,3, . ., 5)$ to $\mathrm{X}_{1 \mathrm{t}}$. If the measure of volatility $Y_{1 t}^{2}$ is significant $\left(\beta_{i} \neq 0\right)$, a linear relationship between $Y_{1 t}^{2}$ and $Y_{2 t}^{2}, Y_{3 t}^{2}$, $Y_{4 t}^{2}$ and $Y_{5 t}^{2}$ is established for obvious reason that either one or more of the component variables at time $t$ contribute to the volatility of the IGR at the same time period t. Hence,

$$
Y_{1 t}^{2}=\alpha_{1}+\alpha_{2} Y_{2 t}^{2}+\alpha_{3} Y_{3 t}^{2}+\alpha_{4} Y_{4 t}^{2}+\alpha_{5} Y_{5 t}^{2}+u_{t}
$$

Where $Y_{1 t}^{2}$ is a measure of volatility of IGR; $Y_{2 t}^{2}, Y_{3 t}^{2}$, $Y_{4 t}^{2}$ and $Y_{5 t}^{2}$ are volatilities of Tax Revenue, Fines \& Fees, Licences and Earnings \& Sales respectively;

$\alpha_{i} \geq 0(i=1,2, \ldots, 5) ; u_{t}$ is a white noise process with mean zero and constant variance.

The null hypothesis $\mathrm{H}_{0}: \alpha_{i}=0(i=2, \ldots, 5)$ against $\mathrm{H}_{1}$ : $\beta_{i} \neq 0$ can also be tested.

\section{Analysis and Results}

\subsection{Effect of Lagged Variable}

From model 1a, given ARCH (1) model

$Y_{1 t}^{2}=\beta_{0}+\beta_{1} Y_{1 t-1}^{2}+U_{1 t}$, the estimate of the parameters of a linear regression produces the following model

$$
\widehat{Y}_{1 t}^{2}=0.0015+0.275 Y_{1 t-1}^{2} 4
$$

Table 1. Parameter Estimates.

\begin{tabular}{lllll}
\hline Predictor & Coeff. & SE Coeff & T & P \\
\hline Constant & 0.0105 & 0.00302 & 3.48 & 0.001 \\
$Y_{1 t-1}^{2}$ & 0.2747 & 0.1000 & 2.75 & 0.007 \\
\hline
\end{tabular}

$\mathrm{S}=0.0256 \mathrm{R}-\mathrm{Sq}=7.6 \% \mathrm{R}-\mathrm{Sq}(\mathrm{adj})=6.6 \%$

Table 2. Analysis of Variance.

\begin{tabular}{llllll}
\hline Source & DF & SS & MS & F & P \\
\hline Regression & 1 & 0.0049285 & 0.0049285 & 0.007 \\
Residual & 92 & 0.0600840 & 0.0006531 & \\
Total & 93 & 0.0650125 & & \\
\hline
\end{tabular}

Test of Hypothesis:

From model 2

$\mathrm{LM}=n R^{2}=94 * 0.076=7.144, \chi_{k}^{2}=\chi_{1,0.05}^{2}=3.84$

Decision: Using the $\mathrm{T}$ value in Table $1, \mathrm{H}_{0}$ for $\beta_{1}=0$ is rejected.

\subsection{Effects of Revenue Components}

From model 3, the following linear regression model is obtained

$$
\hat{Y}_{1 t}^{2}=0.00088+0.688 Y_{2 t}^{2}+0.0116 Y_{3 t}^{2}-0.00168 Y_{4 t}^{2}-0.00149 Y_{5 t}^{2}
$$

Table 3. Parameter Estimates of Component Factors.

\begin{tabular}{lllll}
\hline Predictor & Coeff. & SE Coeff & T & P \\
\hline Constant & 0.000878 & 0.002505 & 0.35 & 0.727 \\
$Y_{2 t}^{2}$ & 0.68829 & 0.05900 & 11.67 & 0.000 \\
$Y_{3 t}^{2}$ & 0.01161 & 0.01248 & 0.93 & 0.355 \\
$Y_{4 t}^{2}$ & -0.001678 & 0.002734 & -0.61 & 0.541 \\
$Y_{5 t}^{2}$ & -0.0014939 & 0.0008787 & -1.70 & 0.093 \\
\hline
\end{tabular}

$\mathrm{S}=0.0168692 \mathrm{R}-\mathrm{Sq}=60.8 \mathrm{R}-\mathrm{Sq}(\mathrm{adj})=59.0 \%$
Table 4. Analysis of Variance of Regression Components.

\begin{tabular}{llllll}
\hline Source & DF & SS & MS & F & P \\
Regression & 4 & 0.0397046 & 0.0099262 & 34.88 & 0.000 \\
Residual & 90 & 0.0256112 & 0.0002846 & & \\
Total & 94 & 0.0653158 & & & \\
\hline
\end{tabular}

Test of Hypothesis:

From model 2

$\mathrm{LM}=n R^{2}=95 * 0.68=64, \chi_{k}^{2}=\chi_{4,0.05}^{2}=9.49$

Decision: Using the $\mathrm{T}$ values from Table $3, \mathrm{H}_{0}$ rejected for $\beta_{2}=0$, accepted for $\beta_{3}=\beta_{4}=\beta_{5}=0$. 


\subsection{Graphical Presentation of Results}

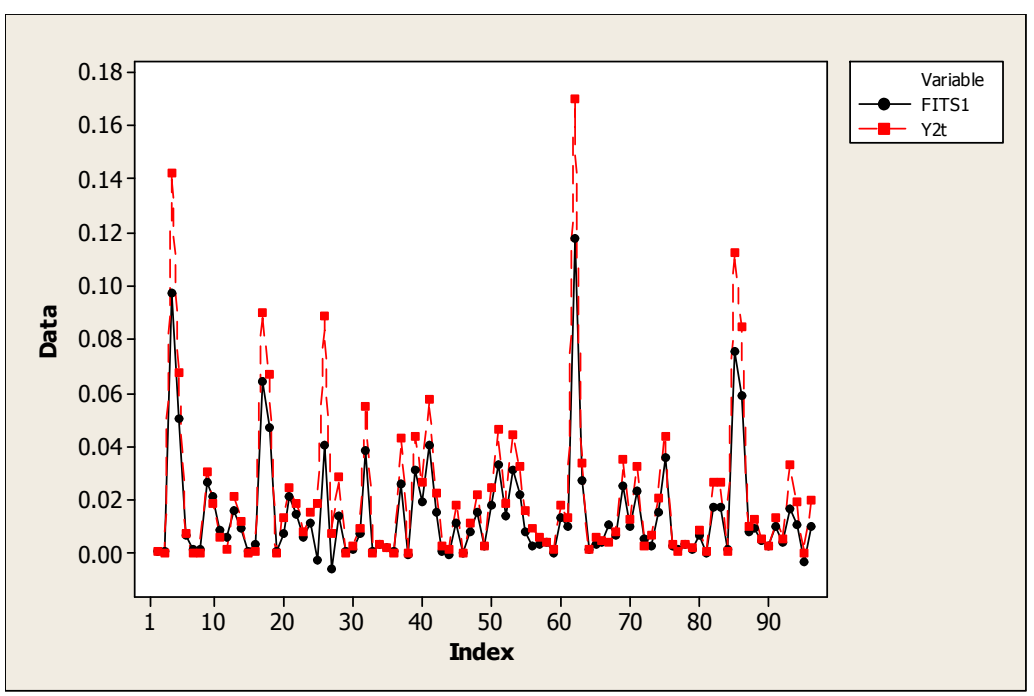

Figure 6. Bivariate Plots of $Y_{2 t}^{2}$ and Estimates of $Y_{1 t}^{2}$.

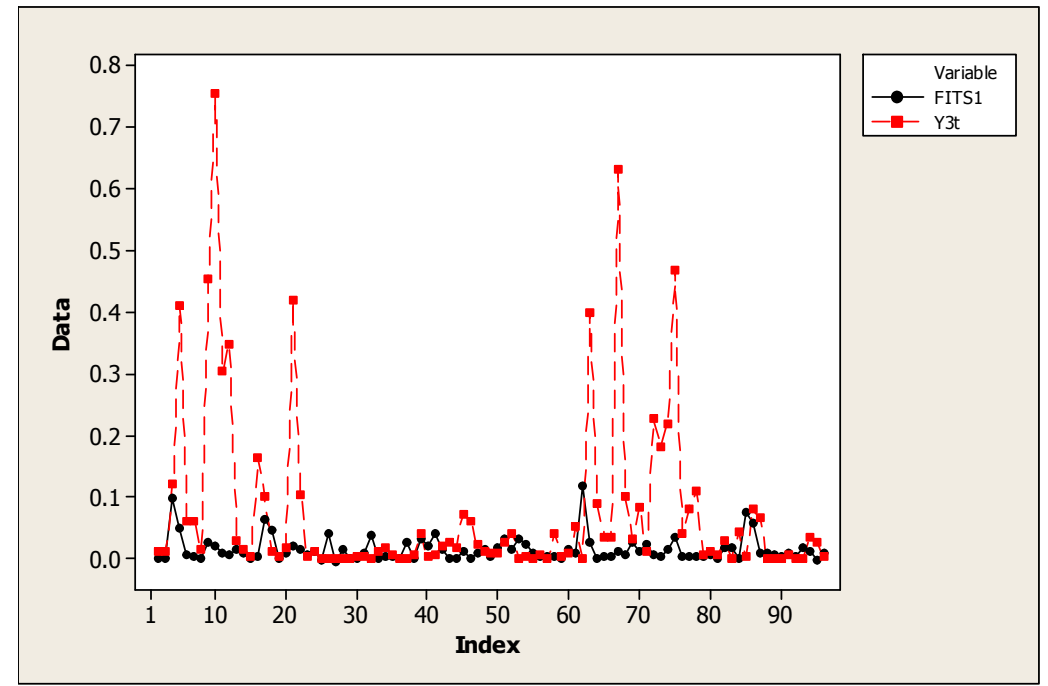

Figure 7. Bivariate Plots of $Y_{3 t}^{2}$ and Estimates of $Y_{1 t}^{2}$.

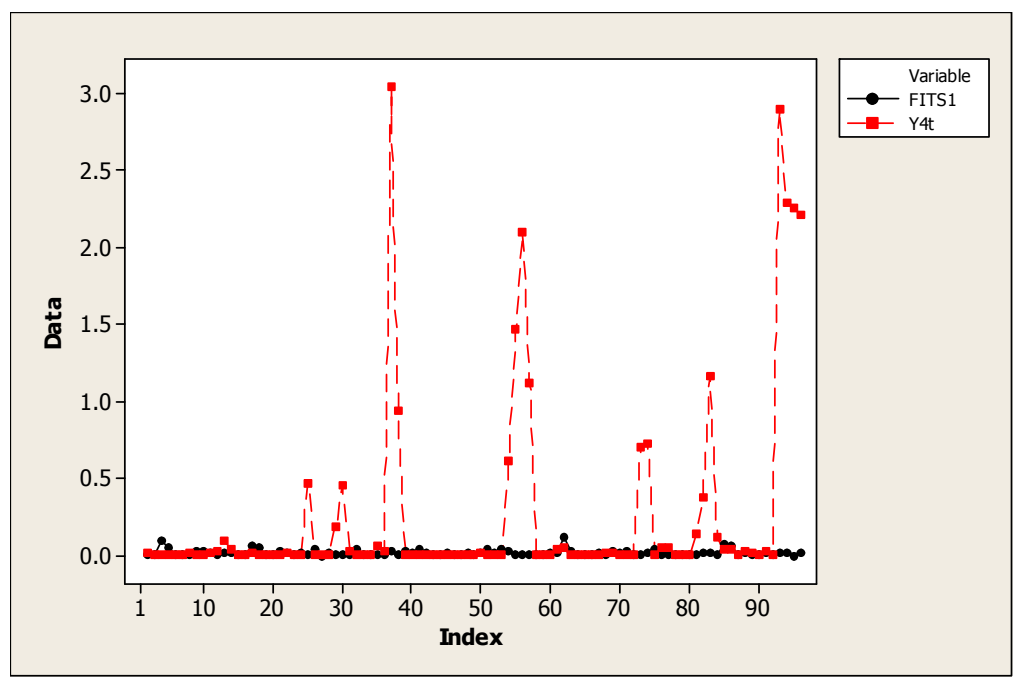

Figure 8. Bivariate Plots of $Y_{4 t}^{2}$ and Estimates of $Y_{1}^{2}$. 


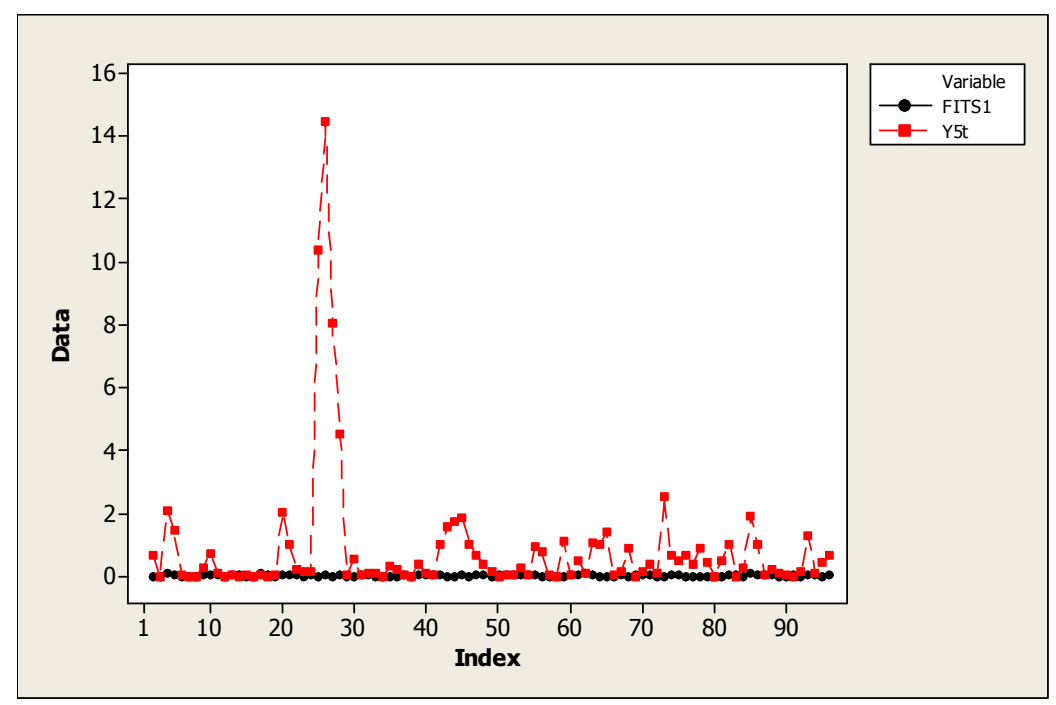

Figure 9. Bivariate Plots of $Y_{5 t}^{2}$ and Estimates of $Y_{1 t}^{2}$.

\section{Discussion of Results}

The measure of volatility of the revenue series established from model 4 is tested to be significant given the information in Tables1 and 2. This explains the ARCH (1) effect in the revenue return series. Higher order ARCH model was verified to be insignificant. Hence, there exists volatility in the revenue return series at $\mathrm{t}-1$ time period. On the assumption that volatility in the revenue series is influenced by one or more of the revenue components, a further regression analysis of volatility measure $Y_{1 t}^{2}$ on $Y_{2 t}^{2}, Y_{3 t}^{2}, Y_{4 t}^{2}$ and $Y_{5 t}^{2}$ has revealed significant effect of Tax revenue volatility at $t$ time period on IGR at the same time period. Analysis of variance test confirms the overall fitness of the regression model. Test for individual coefficient of the regression model was done on the basis of the t- test results in Table 4. Further interpretations of the contributory effects of component volatilities are as shown in Figures 6 to 9 . From Figure 6, it is evident that $Y_{1 t}^{2}$ and $Y_{2 t}^{2}$ are closely associated due to the significant influence of Tax revenue volatility on the volatility of the IGR. Figures 7 to 9 reveal high dispersion of volatilities between IGR and each other component, except Tax revenue. The principal cause of IGR volatility is the Tax revenue volatility.

Analytically, the paper has revealed that the major contribution of volatility in internally generated revenue is the tax revenue. The volatility contributions of other revenue sources are not significant. Hence, volatility in the tax revenue is tantamount to volatility in IGR.

\section{Conclusion}

The aim of the work was to analyse volatility of the Internally generated revenue of Akwa Ibom State with the view to examine the contributions of its components. The result revealed presence of volatility in the IGR. It is an incontrovertible fact that volatility in the IGR is significantly caused by tax revenue volatility. This does not negate volatilities in other revenue components, but it was quite revealing that Tax revenue exerted more influence on the IGR volatility. The volatility in the tax revenue is explained by the inconsistency in the growing trend of the tax revenue. This is attributed to laxities in the revenue generation mechanism, which in effect poses challenges to the revenue system in Akwa Ibom State. The revenue generation system in the state requires sound leadership in the Board of Internal Revenue, good revenue driven policy, transparent tax revenue consulting and innovative approaches by the labour force for smooth and effective revenue generation. Government willingness to address the prevailing issues would enhance stability in the system and would therefore help to cope with the challenges of financial planning in Akwa Ibom State of Nigeria.

Table 5. Revenue Data and Return Series.

\begin{tabular}{|c|c|c|c|c|c|c|c|c|c|}
\hline X1t & $\mathrm{X} 2 \mathrm{t}$ & X3t & $\mathrm{X4t}$ & X5t & R1t & R2t & R3t & R4t & R5t \\
\hline 6.628042 & 4.431677 & 0.098864 & 0.065183 & 0.353994 & & & & & \\
\hline 4.426854 & 4.196096 & 0.128147 & 0.050511 & 0.054482 & -0.17529 & -0.02372 & 0.112669 & -0.11075 & -0.81275 \\
\hline 4.540759 & 4.261585 & 0.167049 & 0.057867 & 0.060485 & 0.011033 & 0.006726 & 0.115136 & 0.059051 & 0.045395 \\
\hline 12.01192 & 10.28981 & 0.076728 & 0.051355 & 1.63875 & 0.422484 & 0.382836 & -0.33789 & -0.05185 & 1.432867 \\
\hline 5.931911 & 5.714923 & 0.343919 & 0.05967 & 0.099817 & -0.30642 & -0.2554 & 0.6515 & 0.065176 & -1.21531 \\
\hline 4.958521 & 4.762915 & 0.2008 & 0.06487 & 0.143247 & -0.07784 & -0.07914 & -0.23369 & 0.036283 & 0.156883 \\
\hline 5.114372 & 4.868107 & 0.362482 & 0.058071 & 0.156291 & 0.01344 & 0.009487 & 0.256522 & -0.04808 & 0.037849 \\
\hline 8.015939 & 7.264263 & 1.376882 & 0.066945 & 0.480046 & 0.193106 & 0.17903 & 0.684192 & -0.04787 & 0.488385 \\
\hline 5.700916 & 5.378268 & 0.191067 & 0.05823 & 0.066306 & -0.14801 & -0.13055 & -0.85771 & -0.06057 & -0.85973 \\
\hline 7.310726 & 6.533925 & 0.697951 & 0.072289 & 0.143826 & 0.108016 & 0.084532 & 0.562639 & 0.093922 & 0.336287 \\
\hline
\end{tabular}




\begin{tabular}{|c|c|c|c|c|c|c|c|c|c|}
\hline X1t & $\mathrm{X2t}$ & X3t & $X 4 t$ & X5t & R1t & R2t & R3t & R4t & R5t \\
\hline 6.275424 & 6.053733 & 0.183887 & 0.050966 & 0.15614 & -0.06632 & -0.03315 & -0.57927 & -0.15179 & 0.035676 \\
\hline 9.057154 & 8.571487 & 0.126901 & 0.105265 & 0.107739 & 0.159349 & 0.151033 & -0.16109 & 0.315005 & -0.16114 \\
\hline 7.135676 & 6.76266 & 0.173596 & 0.06826 & 0.113562 & -0.10356 & -0.10294 & 0.136073 & -0.18812 & 0.02286 \\
\hline 7.098974 & 6.800331 & 0.198206 & 0.070113 & 0.064075 & -0.00224 & 0.002413 & 0.057579 & 0.011635 & -0.24854 \\
\hline 7.911773 & 7.254342 & 0.514912 & 0.08183 & 0.061636 & 0.047078 & 0.028068 & 0.414616 & 0.067111 & -0.01686 \\
\hline 4.007008 & 3.677167 & 0.2547 & 0.062924 & 0.085396 & -0.29545 & -0.29508 & -0.3057 & -0.11409 & 0.141607 \\
\hline 6.999353 & 6.751636 & 0.335336 & 0.075776 & 0.078041 & 0.242238 & 0.263896 & 0.119452 & 0.080716 & -0.03912 \\
\hline 7.180575 & 6.88435 & 0.381589 & 0.092181 & 0.094179 & 0.011101 & 0.008454 & 0.056115 & 0.085109 & 0.081631 \\
\hline 8.327977 & 5.327166 & 0.526796 & 0.07823 & 2.429339 & 0.06438 & -0.11137 & 0.140047 & -0.07127 & 1.411535 \\
\hline 8.67121 & 7.721905 & 0.121809 & 0.076441 & 0.234935 & 0.01754 & 0.161228 & -0.63596 & -0.01005 & -1.01454 \\
\hline 6.800649 & 5.71868 & 0.262086 & 0.096703 & 0.623833 & -0.10553 & -0.13043 & 0.332766 & 0.102111 & 0.424121 \\
\hline 11.21972 & 4.724178 & 0.301425 & 0.086195 & 0.247841 & 0.217432 & -0.08297 & 0.060734 & -0.04996 & -0.4009 \\
\hline 7.496067 & 6.360259 & 0.237454 & 0.078502 & 0.578862 & -0.17515 & 0.129149 & -0.1036 & -0.0406 & 0.368403 \\
\hline 11.94647 & 4.694987 & 0.232554 & 0.016289 & 0.000341 & 0.202406 & -0.13184 & -0.00905 & -0.68299 & -3.2295 \\
\hline 11.91288 & 9.435109 & 0.250312 & 0.017507 & 2.134528 & -0.00122 & 0.303113 & 0.031957 & 0.031328 & 3.796229 \\
\hline 11.99349 & 11.6622 & 0.234253 & 0.020365 & 0.003073 & 0.002929 & 0.092034 & -0.0288 & 0.065667 & -2.8417 \\
\hline 8.768332 & 8.000227 & 0.239928 & 0.023158 & 0.401841 & -0.13603 & -0.16368 & 0.010397 & 0.055807 & 2.116457 \\
\hline 9.859521 & 8.262093 & 0.256296 & 0.062875 & 0.243186 & 0.050939 & 0.013988 & 0.02866 & 0.433783 & -0.21812 \\
\hline 9.320179 & 7.441553 & 0.301272 & 0.013323 & 1.345379 & -0.02443 & -0.04543 & 0.070217 & -0.67389 & 0.742906 \\
\hline 10.94428 & 9.429517 & 0.344274 & 0.018587 & 0.90223 & 0.069763 & 0.102826 & 0.057945 & 0.144616 & -0.17353 \\
\hline 10.12497 & 5.556335 & 0.353957 & 0.019683 & 1.70183 & -0.03379 & -0.2297 & 0.012047 & 0.024877 & 0.275599 \\
\hline 7.114507 & 5.803738 & 0.284453 & 0.022126 & 0.927768 & -0.15325 & 0.018919 & -0.09494 & 0.050817 & -0.26348 \\
\hline 8.62899 & 6.689296 & 0.213136 & 0.02141 & 0.980186 & 0.083815 & 0.061673 & -0.12535 & -0.01428 & 0.023869 \\
\hline 8.14127 & 7.55906 & 0.25736 & 0.012191 & 0.252207 & -0.02527 & 0.053087 & 0.081884 & -0.24456 & -0.58955 \\
\hline 9.247915 & 8.000759 & 0.250898 & 0.017354 & 0.697342 & 0.055352 & 0.024663 & -0.01105 & 0.153361 & 0.441689 \\
\hline 7.205981 & 5.012814 & 0.241067 & 0.968163 & 0.929077 & -0.10835 & -0.20305 & -0.01736 & 1.746539 & 0.124606 \\
\hline 6.487658 & 5.168337 & 0.204796 & 0.103871 & 0.945565 & -0.04561 & 0.013269 & -0.07082 & -0.96945 & 0.00764 \\
\hline 9.175405 & 8.462529 & 0.335157 & 0.108897 & 0.22306 & 0.150537 & 0.214149 & 0.213927 & 0.020521 & -0.62727 \\
\hline 13.37148 & 12.47789 & 0.3032 & 0.115778 & 0.401673 & 0.163554 & 0.168641 & -0.04352 & 0.026609 & 0.255452 \\
\hline 10.77517 & 7.27293 & 0.26566 & 0.125691 & 0.700701 & -0.09376 & -0.23443 & -0.0574 & 0.03568 & 0.24166 \\
\hline 11.04063 & 10.42651 & 0.374165 & 0.109068 & 0.070706 & 0.01057 & 0.156429 & 0.148736 & -0.06161 & -0.99608 \\
\hline 11.41283 & 9.411428 & 0.261888 & 0.093703 & 1.221096 & 0.014399 & -0.04448 & -0.15495 & -0.06595 & 1.237294 \\
\hline 11.00722 & 10.44865 & 0.196948 & 0.099944 & 0.058421 & -0.01572 & 0.045405 & -0.12376 & 0.028006 & -1.32018 \\
\hline 10.01482 & 7.755589 & 0.376041 & 0.104087 & 1.316913 & -0.04103 & -0.12945 & 0.280882 & 0.017637 & 1.352991 \\
\hline 8.173564 & 7.714949 & 0.217676 & 0.08531 & 0.128311 & -0.08823 & -0.00228 & -0.23743 & -0.08639 & -1.01129 \\
\hline 11.49899 & 9.991133 & 0.315619 & 0.076636 & 0.817426 & 0.148248 & 0.112282 & 0.161353 & -0.04656 & 0.804186 \\
\hline 11.0199 & 7.196825 & 0.255926 & 0.086513 & 3.412896 & -0.01848 & -0.14247 & -0.09105 & 0.052648 & 0.620674 \\
\hline 10.18369 & 8.193118 & 0.210204 & 0.10378 & 1.478393 & -0.03427 & 0.056308 & -0.08547 & 0.07903 & -0.36333 \\
\hline 14.58342 & 11.88758 & 0.264145 & 0.083968 & 1.720797 & 0.155954 & 0.161644 & 0.099202 & -0.092 & 0.06594 \\
\hline 12.32322 & 7.3367 & 0.185344 & 0.082845 & 2.313827 & -0.07314 & -0.20959 & -0.15386 & -0.00585 & 0.128601 \\
\hline 12.03523 & 10.1485 & 0.300576 & 0.071446 & 1.380097 & -0.01027 & 0.140901 & 0.209977 & -0.06429 & -0.22442 \\
\hline 19.08946 & 6.316622 & 0.304601 & 0.087346 & 4.218101 & 0.200339 & -0.20592 & 0.005777 & 0.087262 & 0.485207 \\
\hline 16.13557 & 9.660747 & 0.275338 & 0.014455 & 5.942237 & -0.07301 & 0.184526 & -0.04387 & -0.78122 & 0.148833 \\
\hline 15.21658 & 13.09405 & 0.299414 & 0.237178 & 0.631152 & -0.02547 & 0.132063 & 0.036407 & 1.215057 & -0.97382 \\
\hline 12.34154 & 10.60094 & 0.369276 & 0.008492 & 0.08248 & -0.09095 & -0.09173 & 0.091079 & -1.44608 & -0.88378 \\
\hline 13.43093 & 8.954317 & 0.387954 & 0.09779 & 0.052639 & 0.036737 & -0.07331 & 0.021429 & 1.061295 & -0.19505 \\
\hline 13.0814 & 10.48063 & 0.249536 & 0.093958 & 0.0572 & -0.01145 & 0.068355 & -0.19165 & -0.01736 & 0.036095 \\
\hline 14.02346 & 11.53034 & 0.285997 & 0.09033 & 0.66129 & 0.030201 & 0.041455 & 0.059229 & -0.0171 & 1.062993 \\
\hline 12.40674 & 8.58164 & 0.366973 & 0.080488 & 0.887745 & -0.0532 & -0.12827 & 0.108273 & -0.0501 & 0.127896 \\
\hline 8.191152 & 6.64519 & 0.222094 & 0.053588 & 0.178689 & -0.18031 & -0.11106 & -0.2181 & -0.17666 & -0.69619 \\
\hline 18.11649 & 17.3972 & 0.210419 & 0.09014 & 0.080549 & 0.344729 & 0.417972 & -0.02345 & 0.22585 & -0.34604 \\
\hline 14.04695 & 11.52178 & 0.924047 & 0.08459 & 0.872493 & -0.11049 & -0.17896 & 0.64261 & -0.0276 & 1.0347 \\
\hline 15.0027 & 12.64297 & 0.477956 & 0.070281 & 0.083756 & 0.028587 & 0.04033 & -0.28631 & -0.08048 & -1.01775 \\
\hline 15.02994 & 10.69218 & 0.317879 & 0.069138 & 1.282598 & 0.000788 & -0.07278 & -0.17713 & -0.00712 & 1.185075 \\
\hline 15.58784 & 9.255188 & 0.212725 & 0.057961 & 2.104258 & 0.015829 & -0.06268 & -0.17444 & -0.07658 & 0.215008 \\
\hline 15.12586 & 10.87028 & 1.356582 & 0.071857 & 0.910623 & -0.01307 & 0.069855 & 0.804627 & 0.093333 & -0.36376 \\
\hline 15.83296 & 13.56786 & 0.669778 & 0.09813 & 0.100171 & 0.019842 & 0.096271 & -0.30652 & 0.135331 & -0.9586 \\
\hline 12.10786 & 8.929545 & 1.033201 & 0.075661 & 0.110464 & -0.11649 & -0.18168 & 0.188254 & -0.11293 & 0.042478 \\
\hline 9.067575 & 6.977966 & 0.543412 & 0.078253 & 0.257944 & -0.12558 & -0.1071 & -0.27906 & 0.014628 & 0.368306 \\
\hline 13.05671 & 10.70603 & 0.438458 & 0.068201 & 1.048842 & 0.158343 & 0.1859 & -0.0932 & -0.05971 & 0.609185 \\
\hline 13.05854 & 9.587927 & 1.343535 & 0.075017 & 1.879292 & $6.09 \mathrm{E}-05$ & -0.0479 & 0.486321 & 0.04137 & 0.253284 \\
\hline 14.63047 & 11.73833 & 0.515221 & 0.010888 & 0.04781 & 0.049364 & 0.087882 & -0.41626 & -0.8382 & -1.59448 \\
\hline 18.37342 & 16.53875 & 0.179794 & 0.077129 & 0.314817 & 0.098932 & 0.148896 & -0.45722 & 0.850261 & 0.818543 \\
\hline 14.10421 & 10.34785 & 0.890861 & 0.095634 & 1.565798 & -0.11484 & -0.20365 & 0.695036 & 0.093395 & 0.696678 \\
\hline 16.13445 & 11.94653 & 0.578771 & 0.162622 & 0.229948 & 0.058405 & 0.062392 & -0.1873 & 0.230566 & -0.83311 \\
\hline 15.30435 & 12.7645 & 0.307491 & 0.101114 & 0.909826 & -0.02294 & 0.028762 & -0.27467 & -0.20637 & 0.597328 \\
\hline 13.19737 & 11.31414 & 0.677405 & 0.104757 & 0.105594 & -0.06433 & -0.05238 & 0.343016 & 0.015369 & -0.93532 \\
\hline
\end{tabular}




\begin{tabular}{|c|c|c|c|c|c|c|c|c|c|}
\hline X1t & X2t & X3t & $\mathrm{X} 4 \mathrm{t}$ & X5t & R1t & R2t & R3t & R4t & R5t \\
\hline 15.09368 & 12.67423 & 0.58581 & 0.089068 & 0.476924 & 0.058308 & 0.0493 & -0.06309 & -0.07046 & 0.65481 \\
\hline 13.04035 & 10.38197 & 0.46863 & 0.087011 & 0.560272 & -0.06351 & -0.08664 & -0.09693 & -0.01015 & 0.06995 \\
\hline 13.26424 & 11.1182 & 0.402596 & 0.036567 & 0.108725 & 0.007393 & 0.029755 & -0.06596 & -0.37649 & -0.71207 \\
\hline 10.00574 & 7.744969 & 0.610004 & 0.008942 & 1.079053 & -0.12243 & -0.15701 & 0.180463 & -0.61164 & 0.996714 \\
\hline 15.09251 & 11.42934 & 0.596461 & 0.108154 & 0.922669 & 0.178512 & 0.169001 & -0.00975 & 1.082595 & -0.068 \\
\hline 16.04839 & 10.88862 & 0.378473 & 0.241985 & 3.131906 & 0.02667 & -0.02105 & -0.19755 & 0.349747 & 0.530763 \\
\hline 25.15556 & 23.86363 & 0.427697 & 0.154515 & 0.127133 & 0.195203 & 0.340764 & 0.053102 & -0.19482 & -1.39155 \\
\hline 16.03247 & 9.944987 & 0.475159 & 0.109519 & 1.892411 & -0.00509 & -0.09345 & -0.24611 & 0.049803 & 0.190186 \\
\hline 15.03406 & 13.06309 & 0.464333 & 0.075578 & 0.657238 & -0.02792 & 0.118442 & -0.01001 & -0.16109 & -0.45929 \\
\hline 14.14452 & 11.13863 & 0.505637 & 0.099158 & 1.286312 & -0.02649 & -0.06921 & 0.037009 & 0.117932 & 0.291624 \\
\hline 15.06243 & 12.61749 & 0.487904 & 0.089998 & 0.877458 & 0.027307 & 0.054142 & -0.0155 & -0.04209 & -0.16612 \\
\hline 13.06094 & 9.775457 & 0.417347 & 0.130678 & 0.819534 & -0.06192 & -0.11084 & -0.06784 & 0.16197 & -0.02966 \\
\hline 11.01322 & 8.383839 & 0.433396 & 0.149504 & 1.827172 & -0.07406 & -0.06669 & 0.016387 & 0.058449 & 0.348212 \\
\hline 14.12375 & 12.89708 & 0.485518 & 0.002983 & 0.129001 & 0.108036 & 0.187049 & 0.049321 & -1.7 & -1.15119 \\
\hline 11.06636 & 9.666994 & 1.129121 & 0.003082 & 0.013772 & 0.015544 & 0.007822 & 0.16842 & -1.50219 & -0.68042 \\
\hline 15.01937 & 13.51625 & 1.011828 & 0.095011 & 0.089955 & 0.132647 & 0.145565 & -0.04763 & 1.48894 & 0.815027 \\
\hline
\end{tabular}

Table 6. Volatility Measures.

\begin{tabular}{|c|c|c|c|c|}
\hline Y1t & Y2t & Y3t & Y4t & Y5t \\
\hline 0.032037 & 0.000831 & 0.010418 & 0.012646 & 0.650354 \\
\hline $5.38 \mathrm{E}-05$ & $2.64 \mathrm{E}-06$ & 0.010928 & 0.003289 & 0.002672 \\
\hline 0.17538 & 0.142685 & 0.121443 & 0.002868 & 2.071201 \\
\hline 0.096173 & 0.067859 & 0.410753 & 0.004029 & 1.461706 \\
\hline 0.006649 & 0.007096 & 0.059678 & 0.001196 & 0.026629 \\
\hline $9.49 \mathrm{E}-05$ & $1.92 \mathrm{E}-05$ & 0.060478 & 0.002478 & 0.001949 \\
\hline $2.7 \mathrm{E}-06$ & 0.000106 & 0.013267 & 0.011649 & $2.77 \mathrm{E}-05$ \\
\hline 0.035874 & 0.030252 & 0.453727 & 0.002458 & 0.244714 \\
\hline 0.023016 & 0.018401 & 0.753964 & 0.003877 & 0.728346 \\
\hline 0.010882 & 0.006309 & 0.304748 & 0.008505 & 0.117366 \\
\hline 0.004902 & 0.001463 & 0.34795 & 0.023559 & 0.001762 \\
\hline 0.024227 & 0.021296 & 0.029476 & 0.09816 & 0.023976 \\
\hline 0.011504 & 0.011672 & 0.015743 & 0.036031 & 0.00085 \\
\hline $3.53 \mathrm{E}-05$ & 7.22E-06 & 0.002207 & $9.87 \mathrm{E}-05$ & 0.058682 \\
\hline 0.001882 & 0.000528 & 0.163229 & 0.004279 & 0.000111 \\
\hline 0.089493 & 0.090111 & 0.100049 & 0.013408 & 0.021876 \\
\hline 0.0569 & 0.066975 & 0.011849 & 0.006243 & 0.001077 \\
\hline $5.48 \mathrm{E}-05$ & $1.12 \mathrm{E}-05$ & 0.002072 & 0.006957 & 0.007732 \\
\hline 0.003682 & 0.013565 & 0.016757 & 0.005324 & 2.010257 \\
\hline 0.000192 & 0.024376 & 0.418045 & 0.000138 & 1.016549 \\
\hline 0.011931 & 0.018368 & 0.103791 & 0.010082 & 0.185262 \\
\hline 0.045681 & 0.007756 & 0.002513 & 0.002668 & 0.155706 \\
\hline 0.031987 & 0.015388 & 0.013042 & 0.001789 & 0.140402 \\
\hline 0.039484 & 0.018753 & 0.000386 & 0.468795 & 10.38904 \\
\hline $2.42 \mathrm{E}-05$ & 0.088811 & 0.000456 & 0.000878 & 14.45923 \\
\hline $5.94 \mathrm{E}-07$ & 0.007557 & 0.001552 & 0.004092 & 8.039516 \\
\hline 0.019524 & 0.028486 & 4.11E-08 & 0.002928 & 4.506096 \\
\hline 0.002232 & 7.9E-05 & 0.000326 & 0.186695 & 0.044866 \\
\hline 0.000791 & 0.002553 & 0.003554 & 0.456423 & 0.561309 \\
\hline 0.004364 & 0.00955 & 0.002242 & 0.020425 & 0.027965 \\
\hline 0.001406 & 0.055132 & $2.09 \mathrm{E}-06$ & 0.000537 & 0.079467 \\
\hline 0.024633 & 0.000191 & 0.011139 & 0.002412 & 0.06614 \\
\hline 0.006418 & 0.0032 & 0.018483 & 0.000256 & 0.00091 \\
\hline 0.000839 & 0.002303 & 0.005081 & 0.060646 & 0.340183 \\
\hline 0.002668 & 0.000383 & 0.000469 & 0.023001 & 0.200694 \\
\hline 0.012555 & 0.043326 & 0.000782 & 3.044463 & 0.017136 \\
\hline 0.002431 & $6.67 \mathrm{E}-05$ & 0.006629 & 0.943138 & 0.000194 \\
\hline 0.021561 & 0.043702 & 0.041342 & 0.000354 & 0.385604 \\
\hline 0.025553 & 0.026746 & 0.002929 & 0.00062 & 0.068514 \\
\hline 0.009498 & 0.057376 & 0.004624 & 0.001155 & 0.061484 \\
\hline $4.72 \mathrm{E}-05$ & 0.022901 & 0.019082 & 0.004008 & 0.979658 \\
\hline 0.000114 & 0.002459 & 0.027406 & 0.004576 & 1.546525 \\
\hline 0.000377 & 0.001624 & 0.018054 & 0.000692 & 1.726291 \\
\hline 0.002001 & 0.018102 & 0.073053 & 0.000254 & 1.847672 \\
\hline 0.008451 & $5.45 \mathrm{E}-05$ & 0.061516 & 0.007761 & 1.010013 \\
\hline
\end{tabular}




\begin{tabular}{|c|c|c|c|c|}
\hline Y1t & Y2t & Y3t & Y4t & Y5t \\
\hline 0.020894 & 0.011488 & 0.022726 & 0.002329 & 0.656887 \\
\hline 0.000492 & 0.021778 & 0.010332 & 0.002596 & 0.393097 \\
\hline 0.001442 & 0.002622 & 0.00923 & 0.00598 & 0.127473 \\
\hline 0.023181 & 0.024506 & 0.00785 & 0.008779 & 0.005219 \\
\hline 0.005904 & 0.046093 & 0.027049 & 5.7E-05 & 0.018198 \\
\hline 0.000195 & 0.018442 & 0.039751 & 0.004354 & 0.047577 \\
\hline 0.038667 & 0.044528 & 2.33E-05 & 0.007321 & 0.24158 \\
\hline 0.005884 & 0.032194 & 0.002967 & 0.612969 & 0.024066 \\
\hline 0.000851 & 0.01612 & 0.000666 & 1.472235 & 0.936087 \\
\hline 0.008958 & 0.009376 & 0.006477 & 2.096061 & 0.769979 \\
\hline 0.001091 & 0.006148 & 0.000117 & 1.122743 & 0.035625 \\
\hline 0.00023 & 0.004001 & 0.040904 & 0.000363 & 0.001797 \\
\hline 0.000702 & 0.001322 & 0.002365 & 0.000353 & 1.143388 \\
\hline 0.003237 & 0.017788 & 0.00954 & 0.002684 & 0.018009 \\
\hline 0.033861 & 0.013494 & 0.052302 & 0.031812 & 0.475948 \\
\hline 0.116301 & 0.170463 & 0.00116 & 0.050243 & 0.115421 \\
\hline 0.01304 & 0.033878 & 0.399436 & 0.000858 & 1.083682 \\
\hline 0.000619 & 0.001241 & 0.088153 & 0.006754 & 1.023024 \\
\hline $8.48 \mathrm{E}-06$ & 0.006066 & 0.035241 & 7.79E-05 & 1.419375 \\
\hline 0.000147 & 0.004594 & 0.034241 & 0.006128 & 0.048977 \\
\hline 0.000281 & 0.004193 & 0.630479 & 0.008397 & 0.127778 \\
\hline 0.000261 & 0.008312 & 0.100562 & 0.017857 & 0.906871 \\
\hline 0.014447 & 0.034888 & 0.031561 & 0.013139 & 0.002379 \\
\hline 0.016712 & 0.012589 & 0.0839 & 0.000167 & 0.14033 \\
\hline 0.023914 & 0.032689 & 0.010775 & 0.003772 & 0.378822 \\
\hline 1.32E-05 & 0.002809 & 0.22631 & 0.001574 & 0.067384 \\
\hline 0.002085 & 0.006853 & 0.182206 & 0.705433 & 2.522313 \\
\hline 0.009069 & 0.020677 & 0.218855 & 0.720056 & 0.680365 \\
\hline 0.014052 & 0.043578 & 0.468453 & 0.008408 & 0.494178 \\
\hline 0.002993 & 0.003282 & 0.039166 & 0.05238 & 0.683607 \\
\hline 0.00071 & 0.00056 & 0.081381 & 0.043292 & 0.364366 \\
\hline 0.004628 & 0.003304 & 0.1105 & 0.000187 & 0.863076 \\
\hline 0.002982 & 0.001954 & 0.00543 & 0.005207 & 0.437067 \\
\hline 0.004517 & 0.008417 & 0.011562 & 0.00014 & 0.005814 \\
\hline $1.36 \mathrm{E}-05$ & 0.000608 & 0.005861 & 0.143025 & 0.498111 \\
\hline 0.01591 & 0.026281 & 0.028853 & 0.376189 & 1.006037 \\
\hline 0.030559 & 0.026864 & 0.000414 & 1.168334 & 0.003807 \\
\hline 0.000528 & 0.000684 & 0.043325 & 0.121137 & 0.288436 \\
\hline 0.036673 & 0.11267 & 0.001806 & 0.03862 & 1.918924 \\
\hline 0.037729 & 0.085136 & 0.079079 & 0.040395 & 0.977869 \\
\hline 7.73E-05 & 0.009713 & 0.065898 & 0.002314 & 0.038607 \\
\hline 0.001 & 0.012846 & 0.000425 & 0.026501 & 0.205203 \\
\hline 0.000911 & 0.005523 & 0.000697 & 0.01351 & 0.088759 \\
\hline 0.000557 & 0.002405 & 0.000681 & 0.001918 & 0.025542 \\
\hline 0.004306 & 0.013441 & 0.006152 & 0.025687 & 0.000546 \\
\hline 0.006047 & 0.005154 & $3.35 \mathrm{E}-05$ & 0.00322 & 0.125679 \\
\hline 0.010886 & 0.033105 & 0.001499 & 2.895779 & 1.310766 \\
\hline 0.015672 & 0.019078 & 0.035162 & 2.294235 & 0.081157 \\
\hline 0.00014 & 7.41E-06 & 0.024907 & 2.261697 & 0.454431 \\
\hline 0.016627 & 0.01973 & 0.003391 & 2.211883 & 0.674578 \\
\hline
\end{tabular}

\section{References}

[1] Babatunde S. Omotosho and Sani I. Doguwa (2012): Understanding the Dynamics of Inflation Volatility in Nigeria; A GARCH Perspective. CBN Journal of Applied Statistics, Volume 3, No. 2, pp 51-74.

[2] Bera Anil K. and Higgins, Mathew L. (1997): ARCH and Bilinearity as Competing Models for Nonlinear Dependence. Journal of Business \& Economics Statistics, Volume 15, Issue 1.

[3] Berg, J., Marlin, J, \& Heydarpour, F. (2000): Local Government Tax Policy; Measuring the Efficiency of New

York City's Tax Mix. Public Budgeting \& Finance, 20 (2), 114.

[4] Carroll, D. A. and Goodman, C. B (2011): The Effects of Assessment Quality on Revenue Volatility. Public Budgeting \& Finance, 31 (1), 76-94.

[5] Dahiru A. Bala and Joseph O. Asemota (2013): ExchangeRate Volatility in Nigeria; Application of GARCH Models with Exogenous Break. CBN Journal of Applied Statistics, Volume 4, No. 1, pp 89-116.

[6] Dana AL - Najjar (2016): Modelling and Estimation of Volatility Using ARCH/GARCH Models in Jordan's Stock Market. Asian Journal of Finance \& Accounting, Volume 8, No. 1. 
[7] Faruk, Balli and Rosmy Jean Louis (2015): Modelling the tourism receipt's volatility, Volume 22, Issue 2.

[8] Garrett, T. A. (2009): Evaluating State Tax Revenue Volatility; A Portfolio Approach. Applied Economics letters, 16 (3), 243246.

[9] Granger, C. W. and Anderson, A. P. (1978): Introduction to bilinear time series models. Vandenhoeck and Ruprecht

[10] Gujarati, Damodar N. and Porter, Dawn C. (2009): Basic Econometrics, Fifth Edition.

[11] Isenah, M. Godknows, Agwuegbo, S. O. N. and Adewole, A. P. (2013): Analysis of Nigerian Stock Market Returns Volatility Using Skewed ARMA-GARCH Model. Journal of Nigerian Statistical Association, Volume 25.

[12] Koima J. K, Mwita P. N and Nassiuma, D. K (2015): Volatility Estimation of Stock Prices Using GARCH Method. European Journal of Business Management, Volume 7, No.19.

[13] Lucie NIYIGENA, Marcel Ndengo \& Joseph K Mung'atu (2015): Volatility Modelling of Corporate Income Tax in Rwanda. International Journal of Thesis Projects \& Dissertation, Volume 3, Issue 3, pp54-66.

[14] Rodriguez-Tejedor I. (2012): The Determinants of the Structure of Rainy Day Funds. Public Administration Review, 72 (3), 376-386.

[15] Suliman Zakaria Suliman Abdalla (2012): Modelling
Exchange Rate Volatility Using GARCH Models; Emperical Evidence from Arab Countries. International Journal of Economics and Finance, Volume 4, Number 3.

[16] Usoro, Anthony E. and Awakessien Clement E (2018): Necessary Conditions for Isolation of Special Classes of Bilinear Autoregressive Moving Average Vector (BARMAV) Models. American Journal of Theoretical and Applied Statistics, Vol.7, Issue5, pp 180-187, USA.

[17] Usoro, A. E. and Omekara C. O. (2008): Bilinear autoregressive vector models and their applications to estimation of revenue series. Asian Journal of Mathematics and Statistics 1 (1): 50-56.

[18] Usoro, Anthony E. (2017): Identification of classes of bilinear time series models. Journal of Statistics: Advances in Theory and Application, Vol. 17, Number 2, pp 153- 160, India.

[19] Yan, W (2013): Using Trend Data to Evaluate the Differential Response of State Borrowing to Revenue Volatility. Public Budgeting and Finance, 33 (2), 75-92.

[20] Yaya, O. S. and Shittu, O. I. (2014): Naira Exchange Rate Volatility; Smooth Transition or Linear GARCH Specification. Journal of Nigerian Statistical Association, Volume 26.

[21] Yaya, Olaoluwa S., Shittu Olaurewaju I. and Tumala, Muhammed M. (2015): Comparing Predictive Accuracy of Nonlinear Asymmetric Volatility Models: Evidence from the Nigerian Bank Share Prices. Journal of Nigerian Statistical Association, Volume 27. 